\title{
Article \\ Effects of Microwave Treatment in Immersed Conditions on the Mechanical Properties of Jute Yarn
}

\author{
Felicia Syrén *D, Joel Peterson and Nawar Kadi \\ Department of Textile Technology, Faculty of Textiles, Engineering and Business, University of Borås, \\ SE-501 90 Borås, Sweden; joel.peterson@hb.se (J.P.); nawar.kadi@hb.se (N.K.) \\ * Correspondence: felicia.syren@hb.se
}

check for updates

Citation: Syrén, F.; Peterson, J.; Kadi, N. Effects of Microwave Treatment in Immersed Conditions on the Mechanical Properties of Jute Yarn. Fibers 2021, 9, 40. https://doi.org/ $10.3390 /$ fib 9070040

Academic Editor: Vincenzo Fiore

Received: 18 March 2021

Accepted: 28 May 2021

Published: 1 July 2021

Publisher's Note: MDPI stays neutral with regard to jurisdictional claims in published maps and institutional affiliations.

Copyright: (c) 2021 by the authors. Licensee MDPI, Basel, Switzerland. This article is an open access article distributed under the terms and conditions of the Creative Commons Attribution (CC BY) license (https:/ / creativecommons.org/licenses/by/ $4.0 /)$.

\begin{abstract}
The versatile bast fiber jute has environmental benefits compared to glass fibers. However for jute to be used in a composite, the fiber properties need to be altered. This study aims to improve the mechanical properties of jute yarn to make it more suitable for technical applications as a composite. To alter its mechanical properties, jute yarn was immersed in water during microwave treatment. The time and power of the microwave settings differed between runs. Two states of the yarn were tested: fastened and un-fastened. Tensile testing was used at the yarn and fiber level, followed by Fourier-transform infrared spectroscopy (FTIR) and microscopy. The treatment result demonstrated the ability to increase the elongation of the jute yarn by $70 \%$. The tenacity was also increased by $34 \%$ in the fastened state and $20 \%$ in the un-fastened state. FTIR showed that no change in the molecular structure occurred. The treatments resulted in a change of yarn thickness depending on the state of the yarn. The results indicate that microwave treatment can be used to make jute more suitable for technical applications depending on the microwave treatment parameters.
\end{abstract}

Keywords: microwave treatment; jute; yarn; mechanical properties; tensile testing

\section{Introduction}

Natural fibers are competitive with glass fibers as reinforcement in composites. There are two main reasons for the competitiveness of natural fibers: one is that natural fibers are superior to glass fibers from an environmental sustainability perspective, and the other reason is the cheap price of natural fibers. The properties of the reinforcement in a composite should complement the properties of the matrix phase. Composites using glass fibers as reinforcement require high stiffness. Natural fibers are not as stiff but can still be stiff enough depending on the application as the application determines what properties are desired. The purpose of a composite is to utilize the different properties of the different phases to fabricate a material with enhanced properties, often tailored for a specific purpose.

For composites, bonding issues between the matrix phase and reinforcement must be considered. One reason is that the load transfer between the different phases is the mechanism behind the composite's function of utilizing the characteristics of the ingoing phases. If the mechanical properties of reinforcement of the matrix are too diverse, the risk of detachment at load is increased.

For this reason, the good-enough stiffness of natural fibers can be beneficial as it can minimize the risk of detachment due to the tensile load on the composites that contain a soft, deformable matrix in combination with a stiff reinforcement. Another common bonding issue in composites arises when a hydrophobic matrix, such as most polymers, is combined with a hydrophilic reinforcement, such as natural fibers. If the bonding between the phases is weak, it will lead to poor load transfer between the phases and, therefore, a less-performing composite.

Among the industrially used natural fibers, jute is the cheapest [1] and has a high stiffness compared to other natural fibers. Jute properties can be altered using different 
treatments. For example, when mixing jute with wool in spinning, the jute can be treated with caustic soda for improved crimp, softness, and pliability [2]. Furthermore, for knitting, jute fibers need to be made softer and smoother [3]. A common treatment of jute is wollenisation, in which a strong alkali $(18 \%)$ is used to weaken and crimp the fiber [4]. Good results in increasing both the elongation and tenacity have been achieved through grafting. For example, Khan et al. [5] investigated jute yarn grafted with 1,6-hexanediol diacrylate and found an increase in the tensile strength and elongation at break. Grafting with vinyl monomers has also shown results of increased tensile strength, elongation at break, and water uptake [6].

Disadvantages of jute properties include poor elongation and loss in strength at wetting [7]. If the elongation could be increased, additional application areas for jute would be possible. In order to increase the elongation, studies using chemicals, such as liquid ammonia [7] and sodium hydroxide [8] have succeeded, however, with the effect of decreased or, in the best case, sustained tenacity. Tensile testing of jute yarn at elevated temperatures has shown decreased tenacity with increased temperature [9]. Those tensile tests were done under dry conditions, and the humidity loss was reported as a possible explanation for the loss in stress.

Varieties of properties of several textile materials at different levels have been changed through microwaving. Microwave treatments have been used for changing properties, such as coloring [10], fiber-surface roughness [11], and hydrophilicity [12]. Microwaving has also been used to extract fibers [13] and polysaccharides from algae [14] and to graft polymer on flax fibers [15]. The main advantage of microwaving is that the heating is fast and effective [16]. The heating reaches the entire material at once instead of solely relying on conduction and convection for the heat flow to spread.

Studies of microwave treatments for jute, especially without use of chemicals, are few. The most common is to use microwaving as an accelerator of chemical reactions. It is not common to study the effect of microwaves alone on natural fibers. However, Li et al. (2020) [17], studied microwave treatment with only water for dissolving bamboo pulp. The result was a rougher fiber surface and a higher reactivity of the fibers. They explain their results as an attack on the cellulose fibers from the polarized water molecules that move according to the shifting electrical field. Still, attempts to use microwave treatment on jute yarn to enhance its mechanical properties have not been performed yet.

When investigating the mechanical properties and uncertainties of jute at the fiber and yarn level, Ullah et al. (2017) [18] concluded that it was better to do investigations at the yarn level to produce good products using jute.

In this article, we aim to study the effect of microwave treatment without chemicals on the mechanical properties of jute yarn. The purpose is to find out whether the jute properties can be altered.

\section{Materials and Methods}

\subsection{Materials}

Jute yarn of 4475 dTex and twist number 120 was used for samples for the microwave treatments. The samples were soaked and microwave treated in water with a hardness of $3^{\circ} \mathrm{dH}, \mathrm{pH}$ was 8.1 at 24.1 degrees Celsius and alkalinity of $58 \mathrm{mg} \mathrm{HCO} / \mathrm{L}$ The microwave used for the treatments was a Samsung M1727N with a microwave output of $800 \mathrm{~W}$.

\subsection{Methods}

\subsubsection{Microwave Treatment Procedure}

Before the microwave treatment, the samples were soaked in water for $24 \mathrm{~h}$. To enable the full absorption of water, we ensured that the samples were well covered by water. During the microwave treatment, a length of $30 \mathrm{~m}$ of yarn was used with a water amount of $2 \mathrm{~L}$. The yarn treatment was done under loose (un-fastened) and fastened conditions. After treatment, the samples were dried at room temperature for about one week until the weight gain from immersion was gone. 
Before tensile testing, the samples were conditioned at $50 \%$ humidity and $24{ }^{\circ} \mathrm{C}$ for $24 \mathrm{~h}$. During the conditioning, there is a sorption process of water vapor from the lab atmosphere leading to an increase in the yarn weight of $1 \%$. Weighing of the samples before soaking, after soaking, after drying, and after conditioning ensured that the samples had their initial moisture content before conditioning for tensile testing. A reference sample was neither soaked nor microwave treated. Figure 1 shows the treatment procedure.
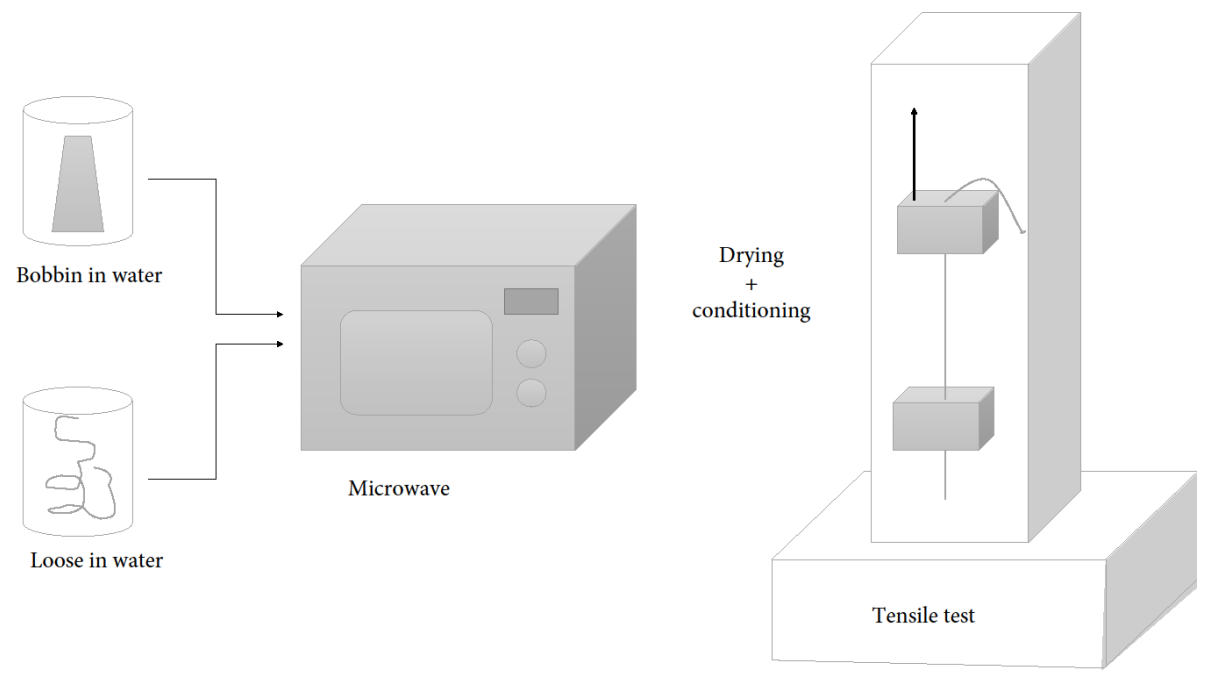

Figure 1. Schematic description of the treatment procedure.

Regarding the microwave treatment, there were two treatment factors: Time and Power. The objective for the first three treatments $(0,1$, and 2$)$ was to investigate the effect of energy uptake augmentation. After, different combinations of time and power were tested but with the same energy uptake. Lastly, one test with high energy uptake was performed.

Since not all microwaves will reach the water and increase its heat, the efficiency of the microwave was investigated and can be seen in Table 1. The efficiency of the microwave was calculated from the theoretical energy, calculated using Equation (1)

$$
E=P t
$$

The experimentally determined power from the average of three runs with $500 \mathrm{~g}$ of water at each power level where the temperature before and after microwaving was used, using Equation (2)

$$
P=\mathrm{c} m \Delta T / t, c=4190 \mathrm{~J} / \mathrm{kgK} .
$$

Table 1. The efficiency of the microwave for the used power settings.

\begin{tabular}{cc}
\hline Power Setting of Microwave $[W]$ & Efficiency $\left(\mathbf{P}_{\text {experimental }} / \mathbf{P}_{\text {theoretical }}\right)$ \\
\hline 450 & 0.715 \\
600 & 0.786 \\
800 & 0.7825 \\
\hline
\end{tabular}

The theoretical energy output in each treatment combination was multiplied with the efficiency factor(s) corresponding to each power setting. For treatment combinations containing more than one power level, the energy from each level was calculated and summed. The resulting energies were assumed to reach the container with water and yarn. This is called the Energy uptake and can be seen in Table 2. In total, six treatment combinations are summarized in Table 2, where each treatment combination number 
is performed in two states (fastened and un-fastened) with twelve repetitions of each combination. The experimental steps of the treatment are illustrated in Figure 2.

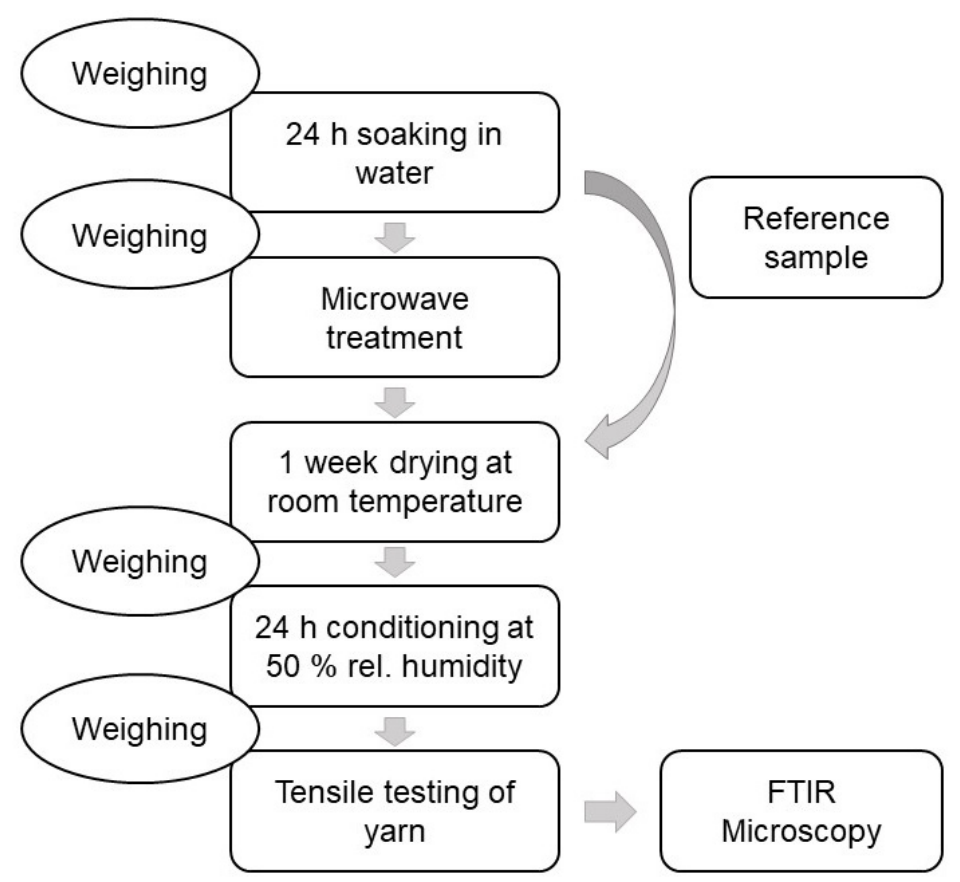

Figure 2. Schematic of the experiment steps and analysis.

Table 2. Combinations of the treatment series.

\begin{tabular}{cccccc}
\hline $\begin{array}{c}\text { Treatment Combination } \\
\text { Number }\end{array}$ & Yarn Length [m] & $\begin{array}{c}\text { Water Quantities } \\
{[\text { liter] }}\end{array}$ & Time [s] & $\begin{array}{c}\text { Power [W] } \\
\text { (Theoretical) }\end{array}$ & $\begin{array}{c}\text { Energy Uptake } \\
{[\mathbf{k J}]}\end{array}$ \\
\hline 0 L/0 B & 30 & 2 & 0 & 0 & 0 \\
1 L/1 B & 30 & 2 & 60 & 450 & 19.2 \\
2 L/2 B & 30 & 2 & 100 & 800 & 60 \\
3 L/3 B & 30 & 2 & $50+50$ & $800+800$ & 60 \\
4 L/4 B & 30 & 2 & $60+90$ & $450+600$ & 61.5 \\
5 L/5 B & 30 & 2 & $60+90+180$ & $450+600+800$ & 173.1 \\
\hline
\end{tabular}

\subsubsection{Tensile Test}

Tensile testing was used at the yarn level. For testing, a tensile tester from Mesdan with pneumatic clamps and a $0.1 \mathrm{kN}$ load cell was used and can be seen in Figure 3. ISO standard 2062 Traction of yarns was chosen. The tensile tester was situated in a controlled environment of $59 \%$ relative humidity and $20^{\circ} \mathrm{C}$.

\subsubsection{Fourier-Transform Infrared Spectroscopy (FTIR)}

A Nicolet iS10 FTIR Spectrometer was used to investigate possible changes in the chemical structure due to the treatment combinations. The spectroscopy was performed in the air without a controlled environment; therefore, the relative humidity was $45 \%$, and the temperature was $20^{\circ} \mathrm{C}$.

\subsubsection{Microscopy}

The yarn thickness and morphology were investigated using a microscope. Five sections of each sample were photographed, and, for each picture, four measurements of the diameter were performed, for a total of 20 measurements of each sample. This was done with a Nikon SMZ800 microscope. 


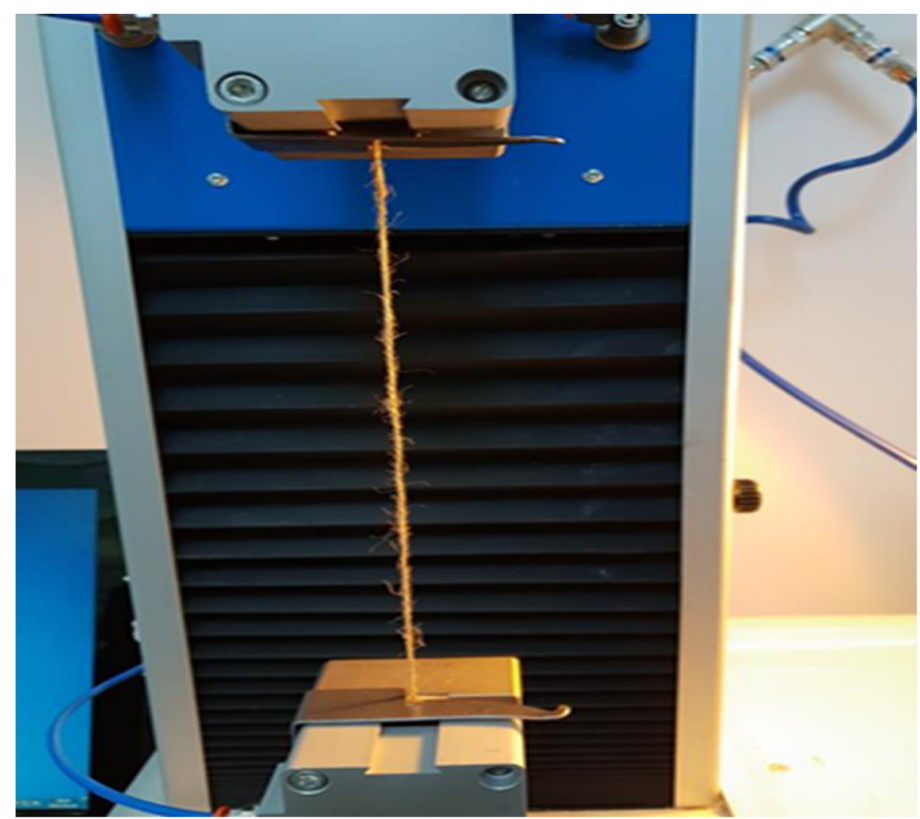

Figure 3. Tensile testing of jute yarn.

\section{Results and Discussion}

The tests were performed as previously described in Table 2, where the treatment combinations were performed with the yarn in the un-fastened and fastened state. To investigate the effects of microwave treatment, tensile tests were performed for un-fastened and fastened yarn. The results from this (the tenacity and elongation) are presented in Table 3 under the un-fastened conditions and Table 4 under the fastened conditions. For both the fastened and un-fastened states, the treatment combinations showed an increase in both the elongation and tenacity.

An increase in both the elongation and tenacity is not common, as most reported treatments with chemicals without grafting show sustained or decreased tenacity when the elongation is increased. The chemicals likely destroy the jute. Wetting is also known to decrease the strength of jute yarn, although Ben Smail (2019) [9] mentioned that strength loss at higher temperatures could be due to humidity loss. The treatments in water with the microwave reported in this study showed an increase in strength supporting the idea of humidity as a factor for maintaining the strength. However, the temperatures used by Smail (2019) [9] were much higher than those reached in this study.

Table 3. The tensile testing results for un-fastened yarn after treatment.

\begin{tabular}{|c|c|c|c|c|c|}
\hline Treatment Combination & Time [s] & Power [W] (Theoretical) & Energy Uptake [kJ] & Tenacity [cN/tex] & Elongation [\%] \\
\hline $0 \mathrm{~L}$ & 0 & 0 & 0 & 9.18 & 2.88 \\
\hline $1 \mathrm{~L}$ & 60 & 450 & 19.2 & 11.01 & 4.95 \\
\hline $2 \mathrm{~L}$ & 100 & 800 & 60 & 9.81 & 4.41 \\
\hline $3 \mathrm{~L}$ & $50+50$ & $800+800$ & 60 & 10.39 & 4.61 \\
\hline $4 \mathrm{~L}$ & $60+90$ & $450+600$ & 61.5 & 10.20 & 4.61 \\
\hline $5 \mathrm{~L}$ & $60+90+180$ & $450+600+800$ & 173.1 & 10.12 & 4.43 \\
\hline
\end{tabular}

Table 4. The tensile testing results for fastened yarn after treatment.

\begin{tabular}{cccccc}
\hline Treatment Combination & Time [s] & Power [W] (Theoretical) & Energy Uptake [kJ] & Tenacity [cN/tex] & Elongation [\%] \\
\hline 0 B & 0 & 0 & 0 & 9.18 & 2.88 \\
1 B & 60 & 450 & 19.2 & 60 & 11.44 \\
2 B & 100 & 800 & 60 & 11.13 & 3.07 \\
3 B & $50+50$ & $450+600$ & 61.5 & 12.34 & 2.96 \\
4 B & $60+90$ & $450+600+800$ & 173.1 & 10.11 & 3.12 \\
5 B & $60+90+180$ & & &
\end{tabular}




\subsection{Effect of Treatment on the Tenacity and Elongation}

Figure 4 shows the effects of the different treatments on the yarn tenacity, where the state of the yarn during microwave treatment is indicated with the color blue for fastened and red for un-fastened. The state of the yarn affected the tenacity for the treatment combinations 2, 3, and 4, which are the intermediate energy output treatments. At the low and high energy output levels, factors other than the state of yarn appeared to dominate the change in tenacity.

The highest tenacity was found for the yarn treated in the fastened state, where it was $12.34 \mathrm{cN} /$ tex under the treatment $4 \mathrm{~B}$, which is an augmentation of $34 \%$ compared to the reference specimen. For the un-fastened state, there was an augmentation of $20 \%$ with treatment number $1 \mathrm{~L}$. It is noteworthy that these increases were after treatments in water, as jute normally show a decrease in strength upon wetting.

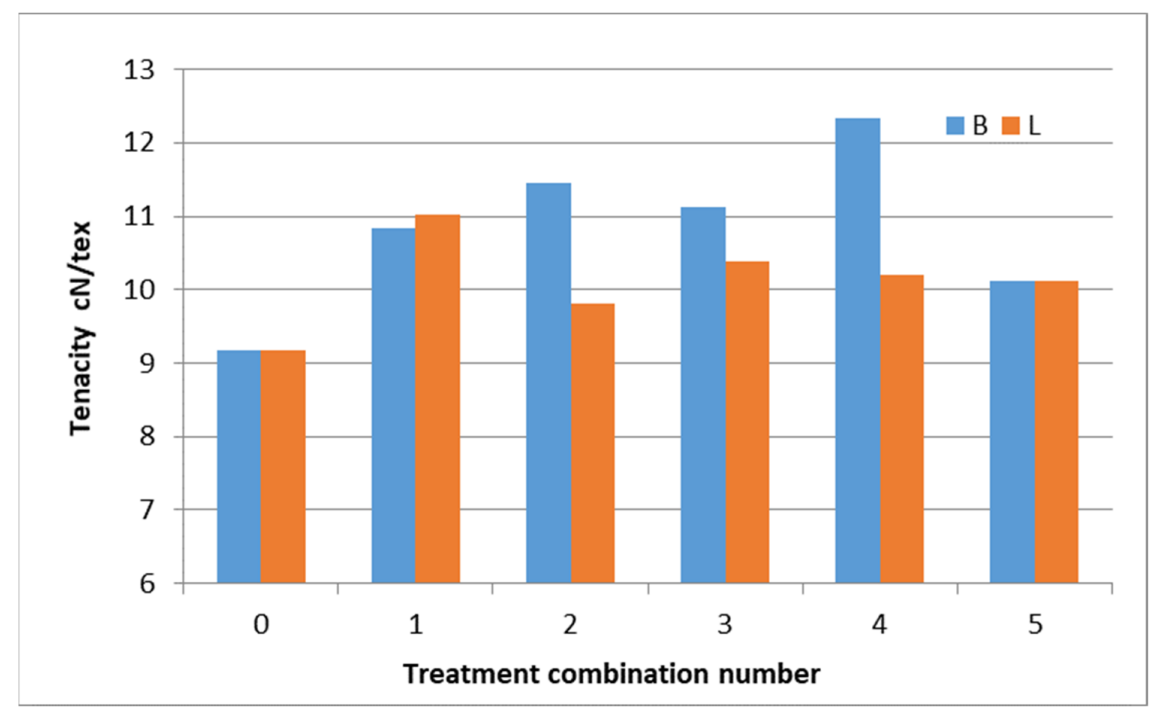

Figure 4. The effects of yarn treatments on the tenacity.

Regarding the elongation (Figure 5), there was no real effective treatment under the fastened state of yarn. On other hand, the effect was remarkable under the un-fastened state, where the $1 \mathrm{~L}$ treatment leads to a $70 \%$ augmentation compared to the reference yarn. It is possible to increase the jute yarn elongation without the use of chemicals.

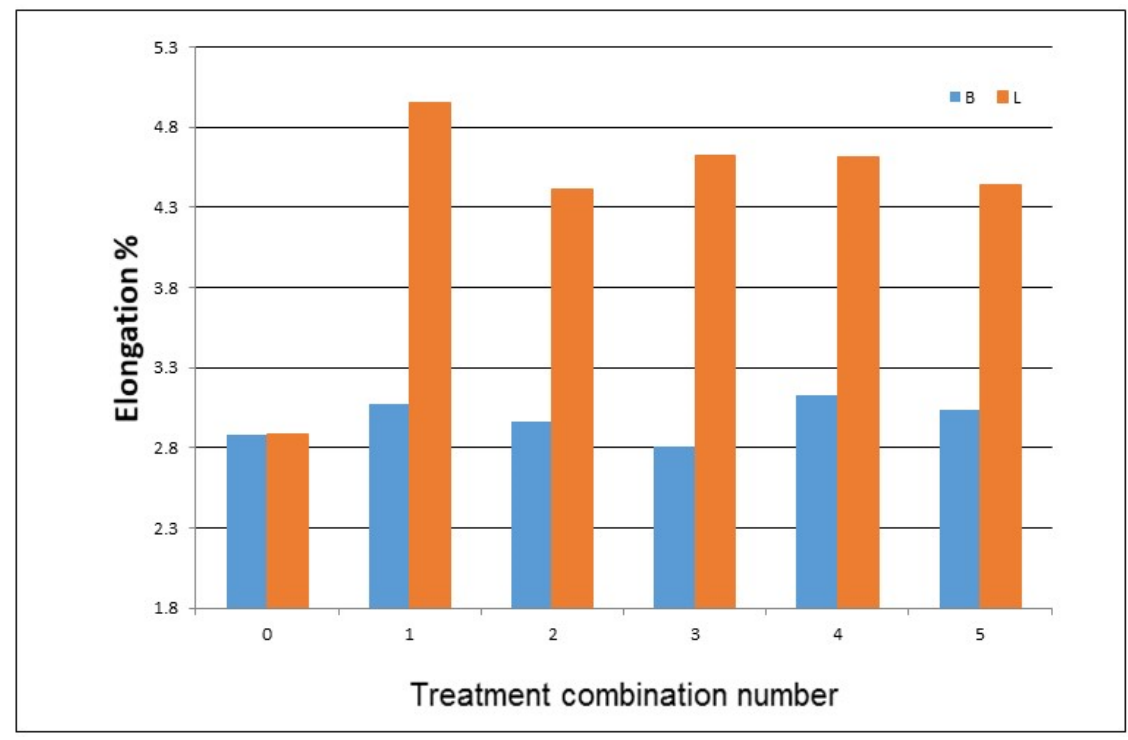

Figure 5. The effects of yarn treatment on the elongation. 
To better understand the effects of the treatment, the effect of energy uptake on the tenacity was investigated. In Figure 6, it can be seen that the largest effect is in zone 1, at about $60 \mathrm{~kJ}$. Comparison of Figure 6 and Tables 3 and 4 makes it possible to identify the method of application as an important parameter in effecting the tenacity. The best results were achieved through a two-step treatment with lower energy the first time.

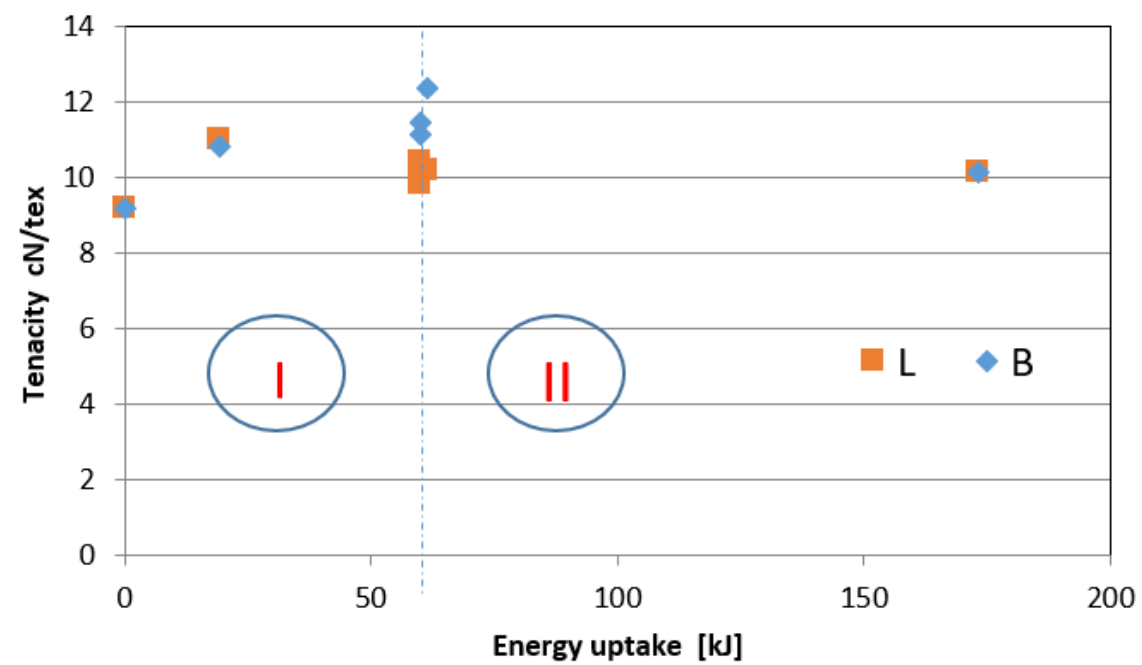

Figure 6. The effects of the energy uptake on the tenacity.

Figure 7 presents the effects of the energy uptake on the elongation, and it can be seen here that the largest effect was also in zone 1 with lower energies below $60 \mathrm{~kJ}$. The highest elongation was achieved at $20 \mathrm{~kJ}$ energy uptake, and it was not a two-step treatment. This means that the resulting jute yarn properties of elongation and tenacity could probably be tailored by a careful choice of treatment regarding the total energy and number of treatments.

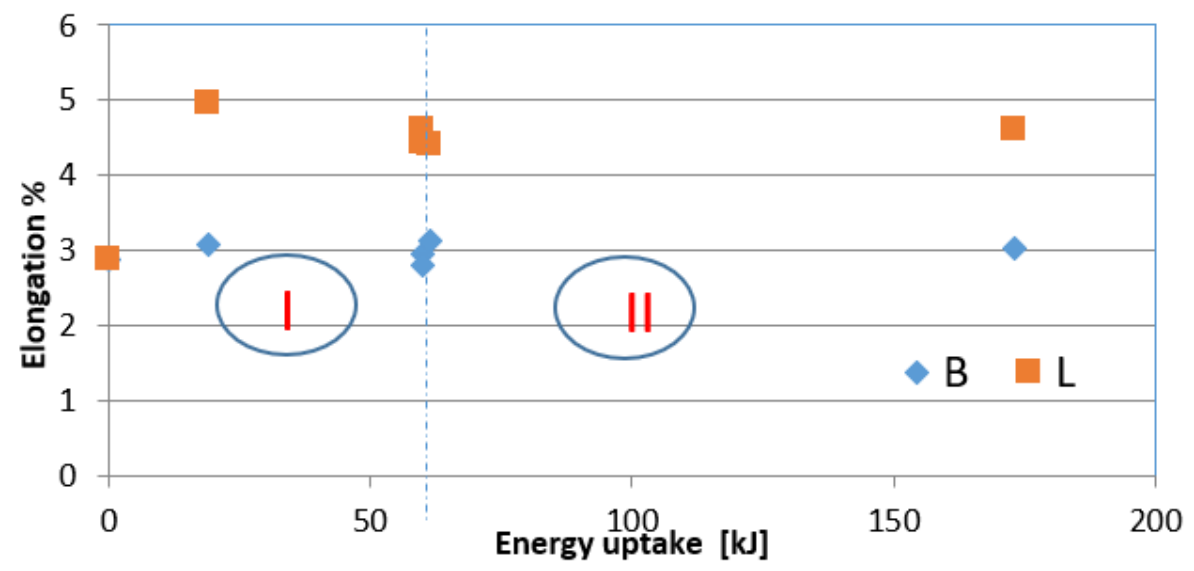

Figure 7. The effects of the energy uptake on the elongation.

Treatments of the same energy with different microwave settings in time and effect produced different results in the tensile properties. This is because the effect comes from the water molecule movements induced by the shifting electrical field of the microwave. Therefore, the effect cannot be achieved through traditional heating methods.

\subsection{Microscope}

An optical microscope was used to measure the thickness of the treated yarn. The yarn thickness was affected by the state of the yarn during treatment. This can be seen in Figure 8. For the un-fastened state, the resulting yarn thickness was thicker than for the 
yarn treated in the fastened state. An idea for an explanation of the increase in thickness was that the un-fastened state could lead to shrinking in length. The shrinking could then lead to higher measurements of elongation as there was more yarn per length to elongate before the break.

However, this explanation is not fully consistent, as the highest elongation was found in treatment combination with low energy uptake, while the highest thickness was found in the intermediate energy uptake treatments. The thickness was also increased for the fastened state without a corresponding increase in elongation, so there is likely another factor involved in the increase in elongation. The yarn has, at a global level, different abilities to adapt to the treatments depending on the state of yarn. It would be interesting to further investigate these changes at a micro-level.

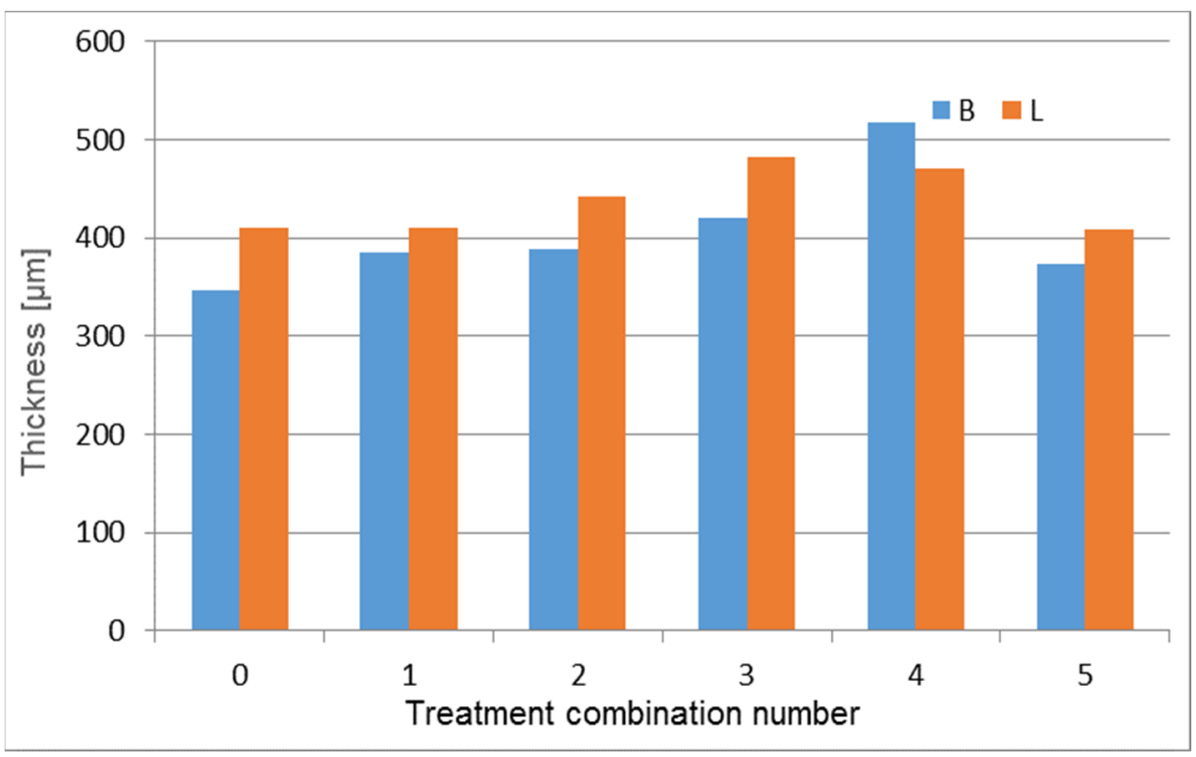

Figure 8. The mean yarn thickness for the treatment combinations. L indicates un-fastened yarn, and $B$ indicates fastened yarn.

\subsection{Fourier-Transform Infrared Spectroscopy (FTIR)}

The FTIR analysis was performed to investigate whether the microwave treatments destroyed the molecular bonds in the jute yarn. We found that there was no destruction of the molecular bonds: the transmittance peaks were of the same size and at the same place for all samples. Figure 9 illustrates the similarity between the samples where the subtraction curve shows small values that could be explained as sample and measurement variation. The temperatures during the microwave treatments were not sufficient to destroy the jute at a molecular level. This could be why there was no reduction in tenacity after treatments that led to increased elongation.

These results are in line with the increased fiber roughness and fiber reactivity after microwave treatments of bamboo fibers reported by Li et al. (2020) [17]. They showed that microwaving had good results for dissolving bamboo pulp at the fiber level, and our work showed that microwaving also had an effect on the properties of jute at the yarn level without destruction of the molecular bonds. The microwave affects the water molecules. Their polarity makes them move and adjust to the shifting electrical field in the microwave.

It is this movement of water molecules around and within the jute fibers that produces an effect in the fiber and yarn properties. To increase the understanding of the phenomenon, it would be interesting to investigate the changes at the fiber/micro-level of the jute yarn to investigate if there are any structural changes. This was out of the scope for this article, as it has been suggested by other authors that the properties at the yarn level of jute are more important than at the fiber level for product quality predictions. 


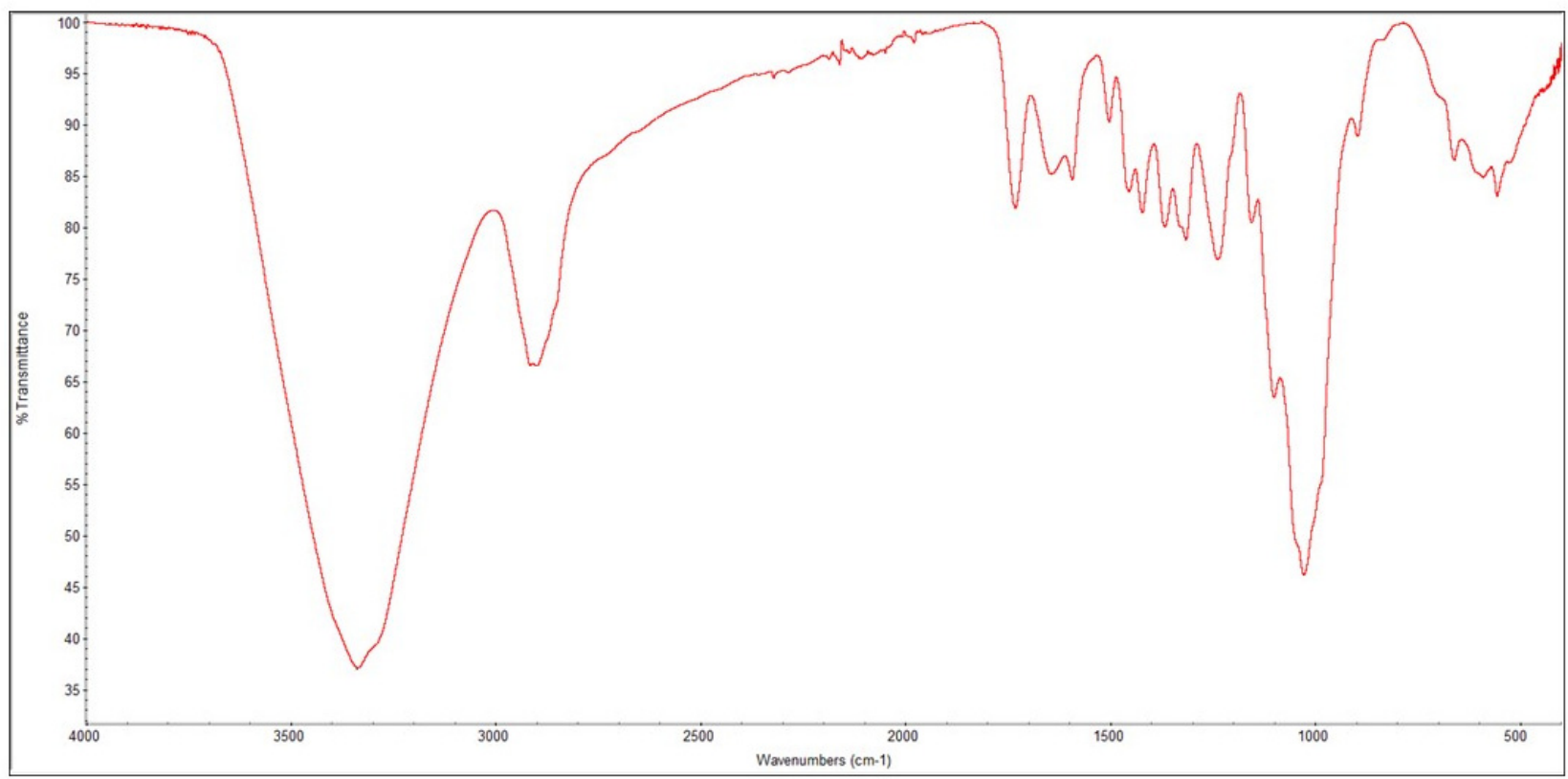

(a) reference sample

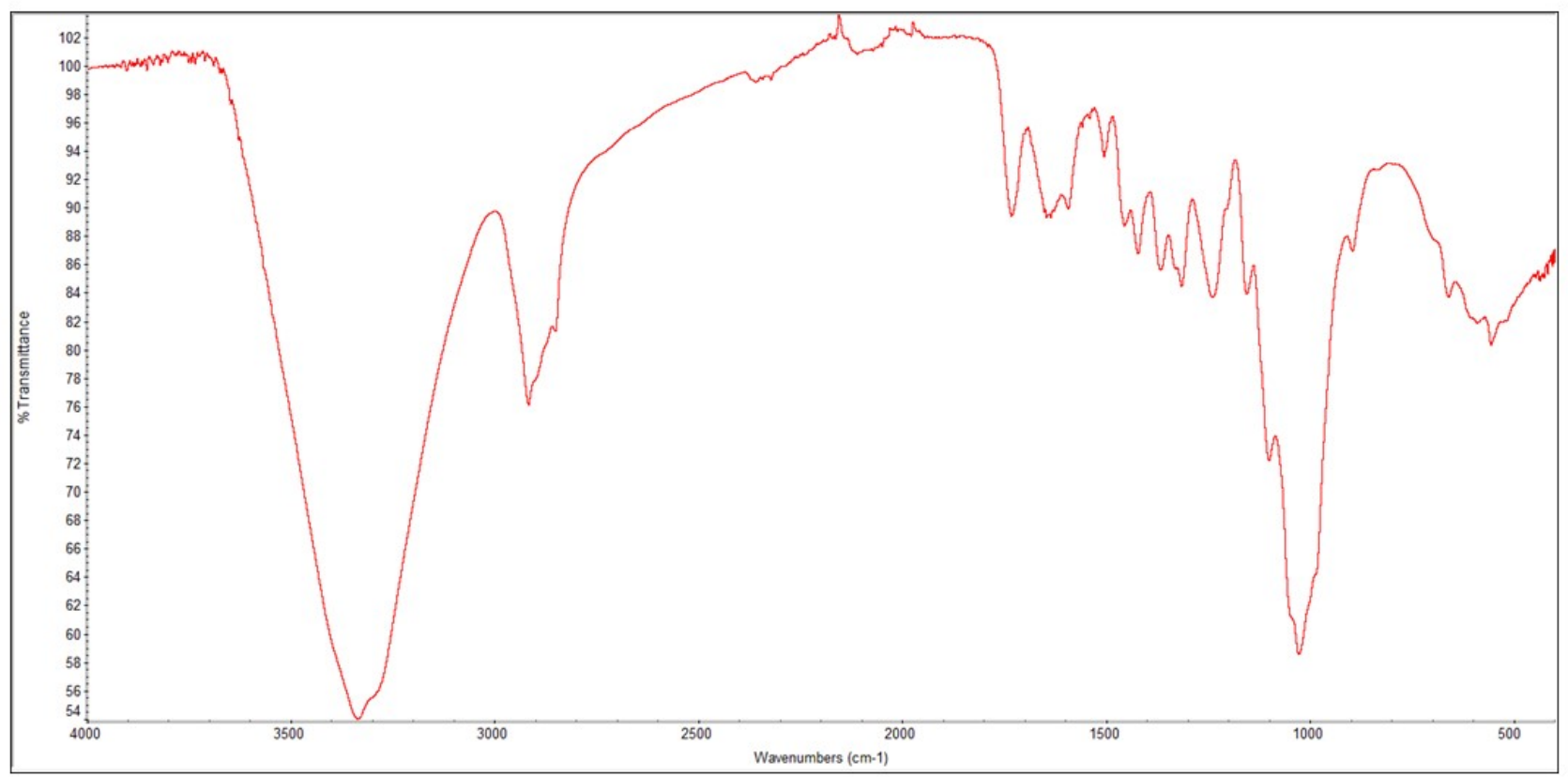

(b) treated sample

Figure 9. Cont. 


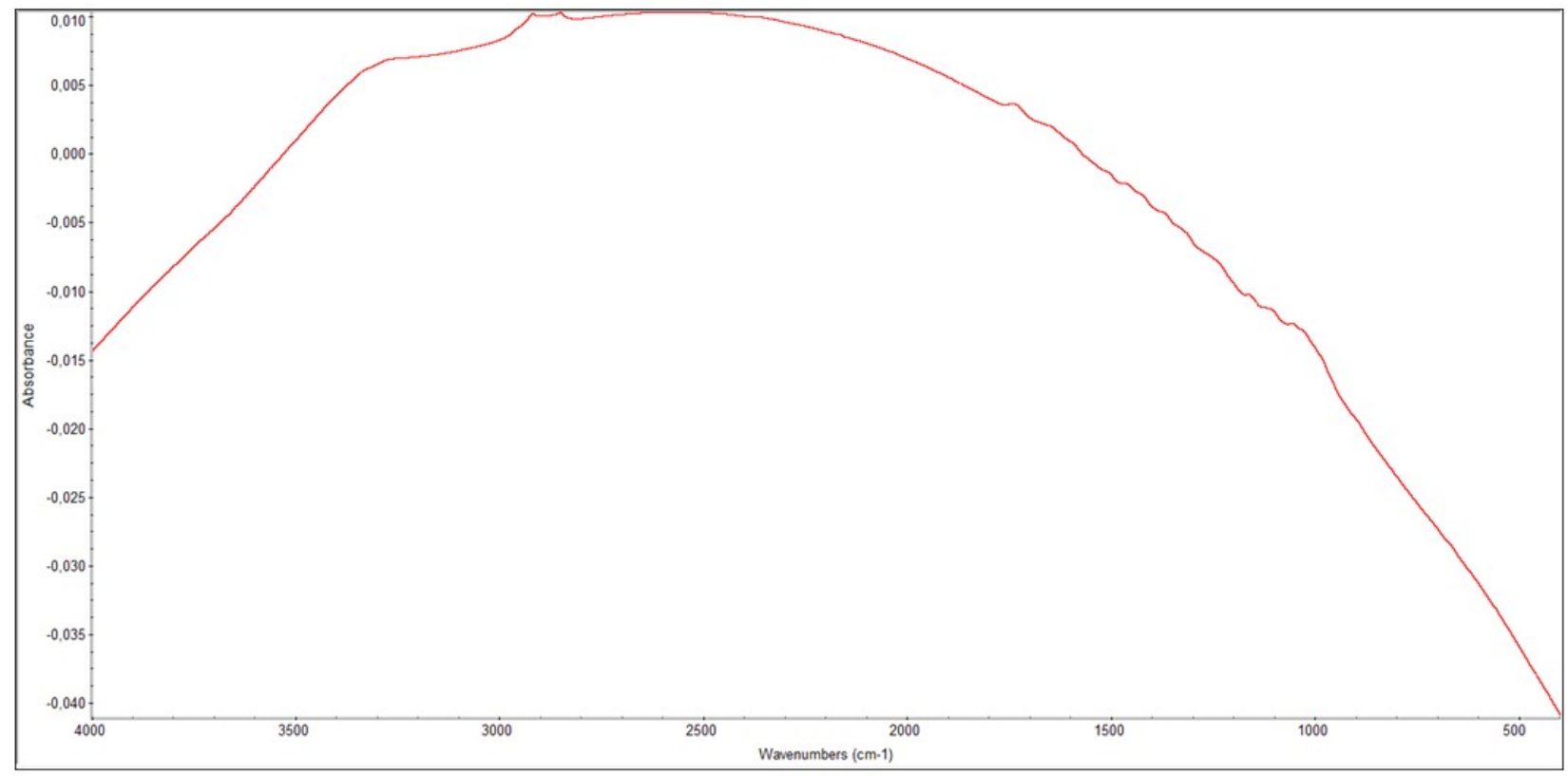

(c) subtraction of samples

Figure 9. FTIR results for untreated and treated jute yarn. (a) FTIR results for the untreated reference sample. (b) FTIR results for a microwave treated sample. (c) FTIR results shown as subtraction of samples.

\section{Conclusions}

We aimed to study the effect of microwave treatments without chemicals on the mechanical properties of jute yarn. The purpose was to determine whether the jute properties could be altered. We demonstrated that the properties of elongation and tenacity of jute yarn could be altered using only a microwave and water.

The tenacity could be increased by microwave treatment, and an increase in elongation could be tailored by the choice of state (fastened or un-fastened) during the treatment. High yarn elongation was achieved by microwave treatment in the un-fastened state. If lower elongation is preferred, this can be achieved by treatment or soaking under tension. The states of the yarn during microwave treatment had a strong effect. The yarn thickness was affected by the state of yarn during treatment.

Future work could investigate the reasons for these results at the structural level of the yarn and fiber, and further experiments with different treatment combinations could provide a better understanding of how the properties of jute yarn can be tailored using only microwaves and water.

Controlling material properties is an important part of controlling product quality. Changing the properties of jute yarn will enable additional application areas for this material, which is already used with large variations. Jute is also an abundant fiber source with environmentally sustainable cultivation. It makes sense to use environmentally sustainable methods for all parts of the product production in order to create a sustainable product from jute. The results of this work can help in finding new application areas of jute with an environmentally sustainable process for changing the material properties.

Author Contributions: Conceptualization, F.S. and N.K.; methodology, F.S.; validation, F.S., J.P., and N.K.; formal analysis, F.S.; investigation, F.S.; resources, F.S.; data curation, F.S.; writing-original draft preparation, F.S.; writing-review and editing, F.S.; visualization, F.S.; supervision, J.P. and N.K.; project administration, N.K.; funding acquisition, N.K. All authors have read and agreed to the published version of the manuscript.

Funding: This research was funded by Åforsk, grant number 19-613. 
Institutional Review Board Statement: Not applicable.

Informed Consent Statement: Not applicable.

Data Availability Statement: Not applicable.

Conflicts of Interest: The authors declare no conflict of interest.

\section{References}

1. Mather, R.R. The Chemistry of Textile Fibres, 2nd ed.; Wardman, R.H., Ed.; Royal Society of Chemistry: Cambridge, UK, 2015.

2. Gullingsrud, A. Sustainable Fibre Toolkit 2018; Rehnby, W., Eriksson, H., Eds.; SST, Stiftelsen Svensk Textilforskning: Stockholm, Sweden, 2018.

3. Roy, A. Development of Knitted Warm Garments from Speciality Jute Yarns. J. Inst. Eng. Ser. E 2013, 94, 61-65. [CrossRef]

4. Ryszard, M.K.O. Handbook of Natural Fibres: Types, Properties and Factors Affecting Breeding and Cultivation Woodhead; Textiles No. 118-119; Woodhead Publishing Ltd.: Cambridge, UK, 2012.

5. Khan, M.A.; Shehrzade, S.; Hassan, M.M. Effect of alkali and ultraviolet (UV) radiation pretreatment on physical and mechanical properties of 1,6-hexanediol diacrylate-grafted jute yarn by UV radiation. J. Appl. Polym. Sci. 2004, 92, 18-24. [CrossRef]

6. Sawpan, M.A.; Khan, M.A.; Abedin, M.Z. Surface modification of jute yarn by photografting of low-glass transition temperature monomers. J. Appl. Polym. Sci. 2003, 87, 993-1000. [CrossRef]

7. Mukherjee, A.C.; Mukhopadhyay, A.K.; Dutt, A.S.; Mukhopadhyay, U. Liquid Ammonia Mercerization of Jute: Part II: A Study of the Effect of Liquid Ammonia on Jute Yarn and Fabric. Text. Res. J. 1981, 51, 574-578. [CrossRef]

8. Gupta, N.P.; Majumdar, A.; Bhattacharya, G.K.; Sur, D.; Roy, D. Chemically Texturizing Jute and Jute-Polypropylene Blended Yarns. Text. Res. J. 1982, 52, 694-702. [CrossRef]

9. Ben Smail, Y.; El Moumen, A.; Lmai, F.; Imad, A. The effects of the temperature on the mechanical properties of natural yarns. MATEC Web Conf. 2019, 286, 3003. [CrossRef]

10. Chattopadhyay, S.N.; Pan, N.C.; Roy, A.K.; Saxena, S.; Khan, A. Development of natural dyed jute fabric with improved colour yield and UV protection characteristics. J. Text. Inst. 2013, 104, 808-818. [CrossRef]

11. Kocak, D.; Merdan, N.; Evren, O.B. Research into the specifications of woven composites obtained from raffia fibers pretreated using the ecological method. Text. Res. J. 2015, 85, 302-315. [CrossRef]

12. Mohammed, A.A.; Bachtiar, D.; Rejab, M.R.M.; Siregar, J.P. Effect of microwave treatment on tensile properties of sugar palm fibre reinforced thermoplastic polyurethane composites. Def. Technol. 2018, 14, 287-290. [CrossRef]

13. Nair, G.R. Role of microwave treatment in the extraction of high quality natural fibers. J. Text. Eng. Fash. Technol. 2017, 2, 333-335. [CrossRef]

14. Li, Z.; Wang, B.; Zhang, Q.; Huang, F.; Ma, J. Microwave-Assisted Extraction and the Antioxidant Activity of Water-Soluble Polysaccharide from Palmaria palmata: Extraction Process and Antioxidant Activity of Polysaccharide from Palmaria palmate. In Proceedings of the 2011 5th International Conference on Bioinformatics and Biomedical Engineering, Wuhan, China, 10-12 May 2011; pp. 1-5.

15. Kaith, B.S.; Singha, A.S.; Kalia, S. Grafting MMA onto flax under the influence of microwave radiation and the use of flax-gpoy(MMA) in preparing PF composites. AUTEX Res. J. 2007, 7, 119-129.

16. Chowdhury, Z.Z.; Abd Hamid, S.B. Preparation and Characterization of Nanocrystalline Cellulose using Ultrasonication Combined with a Microwave-assisted Pretreatment Process. BioResources 2016, 11, 3397-3415. [CrossRef]

17. Li, J.; Tao, T.; Luo, C.; Liu, X.; Zhu, X.; Huang, L.; Ouyang, X.; Ni, Y.; Chen, L. Water molecule "spinning cutter" controllably improving the performance of cellulosic fibers. Cellulose (Lond.) 2020, 27, 7297-7306. [CrossRef]

18. Sharif Ullah, A.M.M.; Shahinur, S.; Haniu, H. On the mechanical properties and uncertainties of jute yarns. Materials 2017, 10, 450. [CrossRef] [PubMed] 